\title{
Article
}

\section{Comparative analysis of existing food safety culture evaluation systems}

Jespersen, Lone, Griffiths, Mansel and Wallace, Carol Anne Available at http://clok.uclan.ac.uk/17678/

Jespersen, Lone, Griffiths, Mansel and Wallace, Carol Anne ORCID: 0000-00021402-2134 (2017) Comparative analysis of existing food safety culture evaluation systems. Food Control, 79 . pp. 371-379. ISSN 0956-7135

It is advisable to refer to the publisher's version if you intend to cite from the work. http://dx.doi.org/10.1016/j.foodcont.2017.03.037

For more information about UCLan's research in this area go to http://www.uclan.ac.uk/researchgroups/ and search for < name of research Group>.

For information about Research generally at UCLan please go to http://www.uclan.ac.uk/research/

All outputs in CLoK are protected by Intellectual Property Rights law, including Copyright law. Copyright, IPR and Moral Rights for the works on this site are retained by the individual authors and/or other copyright owners. Terms and conditions for use of this material are defined in the policies page.

\section{CLoK}

Central Lancashire online Knowledge www.clok.uclan.ac.uk

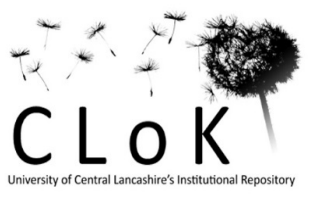




\section{Comparative analysis of existing food safety culture evaluation}

\section{systems}

\section{Author names and affiliations}

4 Lone Jespersen, ${ }^{1}$, Dr. Mansel Griffiths, ${ }^{1}$ and Prof. Carol A Wallace ${ }^{2}$.

51 University of Guelph, 50 Stone Road East, Guelph, ON N1G 2M7, Canada

$6 \quad 2$ University of Central Lancashire, International Institute of Nutritional Sciences and Applied Food

$7 \quad$ Safety Studies, Preston, Lancashire PR1 2HE, United Kingdom.

\section{Corresponding author}

9 Lone Jespersen, University of Guelph, 50 Stone Road East, Guelph, ON, N1G 2M7, Canada.

10 +41792460807. lone@uoguelph.ca

11 Abstract

12 The purpose of the research was firstly, to analyze existing culture evaluation systems for

13 commonalities and differences in research quality, applied validation strategies, and content. Secondly, to

14 suggest a simple structure of food safety cultural dimensions to help unify the culture evaluation field. To

15 achieve these goals, a comparison of eight culture evaluation models applied to varing degrees in the

16 food industry was conducted. The systems were found to vary significantly in applied validation

17 strategies but through deductive, textual data analysis, five dimensions were identified that cover

18 elements present in all the models. Transparency is needed when using applied research methodologies to

19 continually increase quality and trustworthiness of culture research in the food safety domain and this

20 field would benefit from both further commonality of approach to validation strategy and structure and

21 adoption of an overarching structural framework. 


\section{Keywords}

Food safety culture, research quality, trustworthiness, cultural dimensions, culture evaluation

\section{Highlights}

- The research discusses standards and guidelines for evaluating research quality and trustworthiness

- The research compares eight models for evaluating culture for validation strategies and content

- It is discovered that common validation techniques are applied but that only two methods make use of predictive validation.

- Based on a qualitative content analysis of each model a suggested framework of five cultural dimensions are proposed to unify the research field. 


\subsection{Introduction}

The problem of food safety culture - what is it and how do you know how good yours is- is

37 probably one of the main issues in modern thinking about food safety (Christopher James Griffith, 2010;

38 Jespersen, Griffiths, Maclaurin, Chapman, \& Wallace, 2016; Jespersen \& Huffman, 2014; Nyarugwe,

39 Linnemann, Hofstede, Fogliano, \& Luning, 2016; Powell, Jacob, \& Chapman, 2011; Yiannas, 2009).

40 Although it is now subject to much discussion, the concept of food safety culture is still poorly

41 understood. Incidents that prompted attention to food safety culture include, but are not limited to, the

42 listeriosis outbreak 2008- Canada (Canadian Food Inspection, 2013), Melamine posioning 2007 - China

43 (Gossner et al., 2009; Ingelfinger 2008), EHEC outbreak 2011 - Germany (Bernd Appel, 2011; Weiser et

44 al., 2016), Clostridium botulinum, 2013 - New Zealand (Incident, 2014), John Barr 1996 and J.E. Tudor

452005 EHEC outbreaks, U.K. (H. Pennington, 2009; T. H. Pennington, 2014).

Culture, be it organisational, employee health and safety or food safety culture, can be described through Schein's organizational culture definition as a pattern of shared basic assumptions that was learned by a group as it solved its problems of external adaptation and internal integration, that has worked well enough to be considered valid and, therefore, to be taught to new members as the correct way to perceive, think, and feel in relation to those problems (Schein, 2004). As such, culture is

51 formulated in groups, the same groups who often make decisions on how to strengthen culture and invest

52 their resources based on attitudes and assumptions and perhaps the results of culture evaluation systems.

53 Food safety culture has been defined as the aggregation of the prevailing, relatively constant, learned,

54 shared attitudes, values and beliefs contributing to the hygiene behaviours used in a particular food

55 handling environment (C. J. Griffith, K. M. Livesey, \& D. Clayton, 2010a). The definition relates cultural

56 values, beliefs, and learned hygiene behaviour to food. It is often a breakdown of learned and shared

57 attitudes, values, and beliefs that causes deadly failures in food safety management systems and for such 
failures to become embedded in food safety in the food manufacturer's psyche. Evaluating culture is one approach to bring transparency to cultural strengths and weaknesses, which may help prevent consumer illness and mortality due to foodborne illness. Some food manufacturers use cultural evaluation systems to avoid consumers from being exposed to foodborne hazards and for brand protection and employment security (Cameron, 2006; Jespersen \& Huffman, 2014; Seward, 2012). Thus, if cultural evaluation systems are used in this way, it is necessary to determine the trustworthiness of results against accepted methods to assess their validity and reliabililty. scientific theories (De Boeck, Jacxsens, Bollaerts, \& Vlerick, 2015; F. W. Guldenmund, 2000). Many of these evaluation systems are developed using qualitative research methodologies. There is an ongoing need for qualitative research to be demonstrated as a scientifically-based, learned, and robust methodology and this can only be done by recording, systematizing, and disclosing methods of analysis (Attride-Stirling, 2001). It is a concern that some researchers in the culture domain, embrace qualitative methods but do not provide adequate insight into, nor justifications for selected methods, findings, or

72 conclusions; not unlike the approaches taken in other domains, e.g., educational research and employee

73 health and safety (F. W. Guldenmund, 2000; Howe \& Eisenhart, 1990) commonalities and differences in research quality, applied validation strategies, and content; secondly, to suggest a simple structure of food safety cultural dimensions to help unify the culture evaluation field.

\subsection{Research quality}

The National Research Council (NRC) and others have described guidelines that shape scientific 79 understanding and that are frequently used to frame the discourse on the quality of research. This has led 
to the term 'scientifically-based research' being used in some settings to address research quality (Gersten, 2000; Greenhalgh, 1997). Principles for assessing the quality of research include the following:

1. Pose a significant, important question that can be investigated empirically and that contributes to the knowledge base;

2. Test questions that are linked to relevant theory;

3. Apply methods that best address the research questions of interest;

4. Base research on clear chains of inferential reasoning supported and justified by a complete coverage of the relevant literature;

5. Provide the necessary information to reproduce or replicate the study;

6. Ensure the study design, methods, and procedures are sufficiently transparent and ensure an independent, balanced, and objective approach to the research;

7. Provide sufficient description of the sample, the intervention, and any comparison groups;

8. Use appropriate and reliable conceptualization and measurement of variables;

9. Evaluate alternative explanations for any findings;

10. Assess the possible impact of systemic bias;

11. Submit research to a peer-review process;

12. Adhere to quality standards for reporting (i.e., clear, cogent, complete).

While there is no consensus on a specific set of guidelines that will ensure the quality of research, the more research studies are aligned with or respond to these principles, the higher will be the value of the research (Feuer, 2002; Richard J. Shavelson and Lisa Towne, 2002).

\subsection{Research trustworthiness}

Research should be as trustworthy as possible and every research study must be evaluated in relation to the methods used to generate the results. Describing trustworthiness of qualitative research is different than that of quantitative research. Some believe alternative terms are required to evaluate qualitative research (Graneheim, 2004). Regardless of research type, ambiguous or meaningless findings may result in wasted time and effort, while findings that are simply wrong could result in adoption of 
107 dangerous and harmful practices (Long and Johnson, 2000). Untrustworthy research can be caused by

108 error and bias related to both participants and observers (Robson, 2011) and it is the responsibility of the

109 researcher to have a rigorous and transparent validation strategy to eliminate untrustworthy results.

110 Krippendorf reflects on the trustworthyness of scientiffcally-based research by stating quoting from the

111 works of other scholars cannot absolve anyone from the responsibilities for investigating and judging

112 what they thereby enter into literature (Krippendorf, 2004).

\section{$113 \quad 1.3$ Valid and reliable research}

The qualitative researcher must constantly search for techniques to demonstrate rigour of the

115 research process to ensure trustworthiness and usefulness of research findings and to avoid misleading

116 those who use the outcomes of the research (Louis Cohen, 2007; Roberts, 2006). Applying traditional

117 quantitative tests of validity and reliability to qualitative research methods can be difficult, as the

118 subjectivity of respondents' and observers' opinions, attitudes, and perspectives contribute to a degree of

119 bias. Thus, the validity of qualitative research must be seen in relative rather than absolute terms

120 (Gronlund, 1990). This suggests that the quality of trial design could influence the reliability of the final

121 results, which are crucial for their interpretation and subsequent recommendations and implementation

122 (Armijo-Olivo, 2012).

Results and inferences made from any culture evaluation methodology are impacted by the

124 validity and reliability of the research. Researchers must strive to balance the impossibility of reaching

125 100\% validity with avoidance of untrustworthy, invalid research (Louis Cohen, 2007). Validity indicates

126 the system's accuracy; whereas reliability indicates the system's ability to produce consistent and

127 repeatable results (Trochim, 2006). Reliability measures are important parts of the system's overall

128 validity. Reliability is necessary but cannot be considered in isolation. For a system to be reliable, it must

129 be valid. A system can be reliable e.g., through internal consistency but not valid but mostly if it is valid it 
130 is more often than not reliable (Louis Cohen, 2007). However, there is some disagreement with these

131 statements as Robson states that unless a measure is reliable, it cannot be valid (Robson \& Robson,

132 2011). There is general concensus that reliability is necessary but not sufficient. Reliability can also be

133 seen to relate to the coherence theory of truth in social research, i.e. a statement is considered a true

134 representation of a socially constructed reality when it is confirmed by several reports (Richie, 2003) .

135 The concepts of validity and reliability have great importance for evaluating the trustworthiness of any

136 results and inference generated by a culture evaluation system (Robson \& Robson, 2011). The

137 applicability of different validity and reliability measures is directly linked to the type of research

138 conducted. It is therefore important, when developing a culture evaluation system by which organizations

139 plan to introduce change, to consider the full research process including e.g., research questions, data

140 collection, and data analysis, before designing the final research study, selecting methods, and the specific

141 validation and reliability measures necessary to ensure trustworthiness and usefulness of the results

142 (Louis Cohen, 2007; Meyrick, 2006; Robson \& Robson, 2011; T. Long, 2000).

\subsubsection{Validation and validity}

Validity theory has evolved over time (Shepard, 1993, 2016) and it is important to note that many have engaged in the discussion on defining and selecting the most appropriate validation measures and

146 concluded that not one approach fits all situations. It is not the intent of this paper to give a

147 comprehensive review of all validity and reliability measures but a broad enough view to compare and

148 contrast validity of existing culture evaluation systems. Concepts of measuring validity have been applied

149 to various fields of research and it is clear how quantifiable validation tests are a fit with quantitative

150 scientific research but it is less clear what validity measures are a fit for naturalistic and qualitative

151 research carried out by sociologists, psychologists, and other researchers using qualitative techniques.

152 Here it becomes more difficult to meet the expectations of validity as applied to quantitative data.

153 Borsboom, Mellenbergh, and Van Heerden (2004) discuss this and highlight how, in some cases, outright 
154 mistakes were made when applying quantitative validity measures to qualitative research. They also

155 challenge the dependency on correlation as a proof of validity and argue that, simply put, a test is valid

156 for measuring an attribute if variation in the attribute causes variation in the test score. As such, they

157 present an argument for causation and not correlation (Borsboom, 2004). Validity thereby expresses the

158 degree to which the system accurately reflects the value or the change in the measure. Views also exist

159 that qualitative and quantitative data do not calibrate exactly but that this does not undermine either

160 tradition. This view underlines the value of combined approaches, using different forms of evidence for

161 complementary extension of insight of the social world (Richie, 2003). Nevertheless, it is important that

162 each facet of evidence is as valid and reliable as it can be based on the research design and methods used.

\section{$163 \quad$ 2.0Materials and methods}

\subsection{Sample}

Eight culture evaluations systems already applied within the food industry were included in the comparative analysis. Five systems, referred to in this paper by the name of the authors who first

167 described them: Ball, Denison, De Boeck, Jespersen, and Wright, as well as three systems referred to in 168 this paper by their commercial names, CEB, TSI, and NSF. It is important to note that other commercial 169 evaluation systems are available but these three were the most often applied in the food industry and have 170 been included here for reference. Content from these systems was included in the analysis however, 171 details regarding validation strategies either do not exist or are not available and therefore not included in 172 the comparison of applied validation strategies.

$173 \quad 2.2$ Method

A six step process was used for the comparative analysis (Figure 1). To obtain data from existing 175 culture evaluation systems specific to the quality, trustworthiness, and content of each system a structured 176 content analysis was completed. Publically available material was gathered e.g., peer reviewed papers, 
179 Doncaster, Australia, for deductive, textual data analysis. The NVivo software is designed specifically for 180 qualitative coding of textual and other types of qualitative data. A content analysis framework (Table 1)

181 was developed based on initial reading and descriptions of the eight systems. The framework consists of

182 three levels of textual analysis: basic themes, organizing themes, and global themes (Attride-Stirling, 183 2001). 


\begin{tabular}{|c|c|c|}
\hline Global & Organizing & Basic \\
\hline $\begin{array}{l}\text { Values and } \\
\text { Mission }\end{array}$ & $\begin{array}{l}\text { Statements related to; direction, } \\
\text { goals, compliance, improvement, } \\
\text { measures, metrics, plan, roadmap, } \\
\text { long-term plan, long-term direction. } \\
\text { Also, statements as "just the right } \\
\text { thing to do..." }\end{array}$ & $\begin{array}{ll}\text { - } & \text { Compliance. } \\
\text { - } & \text { Measures/metrics/KPIs. } \\
\text { - } & \text { Mission, vision, goals. } \\
\text { - } & \text { Ownership/owning, } \\
\text { - } & \text { Plan/roadmap, direction. } \\
\text { - } & \text { Recall/recalls/withdrawals. } \\
\text { - } & \text { Responsibility, accountability, } \\
\text { - } & \text { Dommitment. } \\
\text { Direction }\end{array}$ \\
\hline $\begin{array}{l}\text { People } \\
\text { Systems }\end{array}$ & $\begin{array}{l}\text { Statements related to; role, group, } \\
\text { team, accepted behaviour, rejected } \\
\text { behaviour, accepted practices, } \\
\text { rejected behaviours, training, } \\
\text { education, learning, consequences, } \\
\text { escalation, celebrations, punishment, } \\
\text { communication, group and } \\
\text { individual pride. }\end{array}$ & 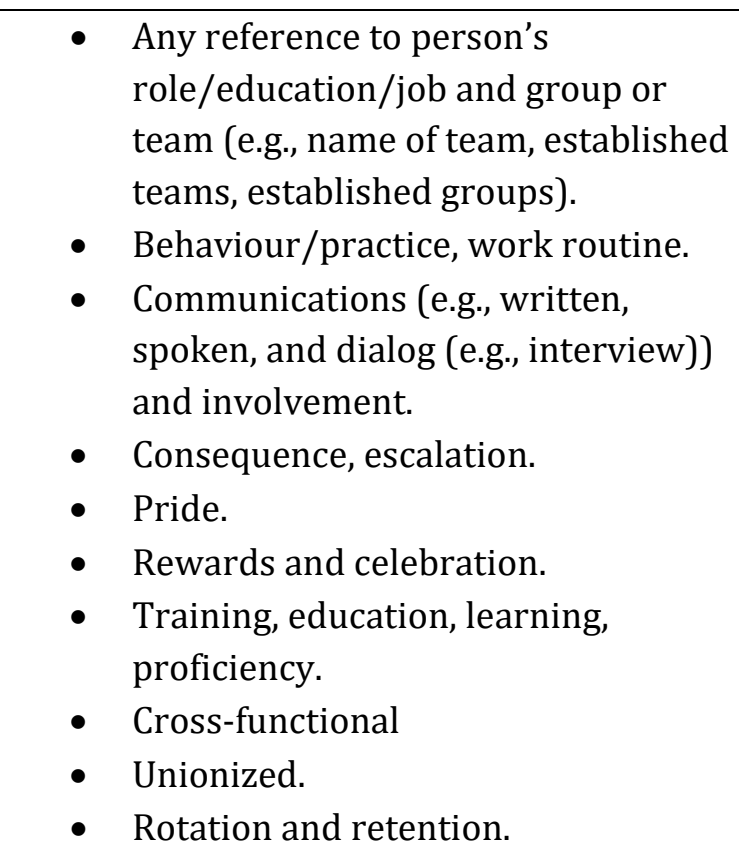 \\
\hline Consistency & $\begin{array}{l}\text { Statements related to; leader } \\
\text { communication of system, leader } \\
\text { communication of system, due date } \\
\text { met, due date missed, tasks, projects, } \\
\text { basic tools missing, basic tools } \\
\text { available, data collection, data } \\
\text { collection tools, data usage, }\end{array}$ & $\begin{array}{l}\text { - Actioned data and performance } \\
\text { metrics. Actions, tasks, action due } \\
\text { date. } \\
\text { - Non-conformance, reoccurring, } \\
\text { - Technology } \\
\text { Tools and infrastructure (missing } \\
\text { infrastructure, appropriate/right } \\
\text { tools, appropriate infrastructure, } \\
\text { missing tools). } \\
\text { - References to third party standards. }\end{array}$ \\
\hline
\end{tabular}




\begin{tabular}{|c|c|c|}
\hline & $\begin{array}{l}\text { performance reports, performance, } \\
\text { decisions and use of technology. }\end{array}$ & \\
\hline Adaptability & $\begin{array}{l}\text { Statements related to, improvement, } \\
\text { continuous improvement, system } \\
\text { improvement, change readiness, } \\
\text { change challenges. Also, look for } \\
\text { readiness in adoption of new tools, } \\
\text { technology, or processes. E.g., will } \\
\text { adopt when there is a legal } \\
\text { requirement but will not take a } \\
\text { broader look to process } \\
\text { improvement investments. }\end{array}$ & $\begin{array}{l}\text { - Change readiness, open to change, } \\
\text { change ready. } \\
\text { Improvement, must improve, } \\
\text { continuous improvement, } \\
\text { improvement process, improvement } \\
\text { system, continuous improvement, } \\
\text { Six Sigma, Lean manufacturing. }\end{array}$ \\
\hline $\begin{array}{l}\text { Risk } \\
\text { awareness }\end{array}$ & $\begin{array}{l}\text { Statements related to; review of } \\
\text { risks, hazards identification and } \\
\text { assessments, risk assessments, } \\
\text { leaders pay attention to control of } \\
\text { risks and hazards, operators pay } \\
\text { attention and speak up if a risk or } \\
\text { hazard gets out of control. }\end{array}$ & $\begin{array}{l}\text { - Leaders risk awareness and } \\
\text { perception. } \\
\text { - } \\
\text { Operator risk awareness and } \\
\text { perception. } \\
\text { - } \text { Risks, hazards. }\end{array}$ \\
\hline
\end{tabular}

The aggregation of basic and organizing themes was used to define the global themes later translated into suggested food safety culture dimensions. The degree of agreement or disagreement in content of each system was evaluated using the coverage of each system for each of the global themes. 
190 Coverage was evaluated by quantifying manifest codes per system per global theme and qualitatively by

191 looking for latent meaning of detailed system content. A summary was written for each system which

192 focused on structure, compliance to the National Research Council (NRC) guidelines, validation

193 strategies, and references to the material included in the comparative analysis. By summarizing the

194 manifest and latent codes per system a comparative figure was developed to visually analyze for

195 agreement or disagreement across the five suggested food safety cultural dimensions.

196

197

\section{Figure 1: Six step process applied in the comparative analysis}

198

1. Identify culture evaluation systems in scope of the analysis.

2. Review publically available material related to research quality, system validation, and content.

3.Develop content analysis framework and textual data analysis in NVivo 11.

4.Summarize NRC compliance, validation strategy, and content for each system, review with experts.

5.Compare and contrast research quality and trustworthiness.

6.Compare and contrast content against global themes. 


\subsection{Research trustworthiness}

A four step validation strategy was applied to assess trustworthiness of the research results;

(1) External population and ecological validity to ensure generalizability. This was achieved

205 through literature review, expert consultation, and coverage of global codes found in each system,

206 analysis and inclusion of language found in content analysis and currently applied in the food safety

207 domain. The experts were chosen for their expertise in the area of culture and independent of the research

208 and/or the models. The experts were trained in the NRC guidelines and reviewed samples of

209 documentation aginst these.

(2) Internal face and construct validity to ensure the content reflects what it is intended to and that

211 the evaluation construct is robust. Peer review was conducted, adding representative quotes linked to the

212 global themes from each evaluation system (Graneheim, 2004). Each system owner was given the

213 opportunity to approve the system summary and assessments.

(3) Internal validity to ensure replicability. This was accomplished through the systemic search

215 and inclusion of most often cited evaluation systems both academic and commercial. Although this, might

216 be influenced by how well a given method is marketed through commercial channels.

(4) Reliability through evaluation of technical accuracy. Group discussions with practitioners and

218 academicians were conducted to ensure that the construct and results are representative of the concept it is 219 intended to measure. 


\subsection{Results}

\section{$221 \quad 3.1$ Summary of in-scope culture evaluation systems}

The following provides a short summary of the eight culture evaluation systems; focus domain,

223 structure, general adherence to the twelve principles in the NRC guidelines, validation strategies, and 224 references.

\subsubsection{Ball model}

This system was developed by Brita Ball in 2009 as part of her doctorate work at the University 227 of Guelph (Ball, Wilcock, \& Aung, 2009; Wilcock, Ball, \& Fajumo, 2011). The system is focused on the 228 food safety domain, specifically food safety climate, and was tested with five food manufacturers in

229 Canada. There is not reference to a definition in the papers and this is likely to be due to the early date of 230 the research when no formal definition had been published. Thirteen in-depth interviews were conducted 231 with five small to medium sized processing plants; together with two focus group sessions with interest 232 groups. The model consists of six themes and 20 sub-themes, each measured through a self-assessment 233 survey, in-depth interviews, field observations, and a second self-assessment survey. Analysis of data 234 generated was conducted in NVivo 7 [Computer Software] QSR International, Doncaster, Australia, by 235 applying validated content analysis principles using both deductive and inductive analysis. Multiple 236 methods of data collection allowed researchers to apply some triangulation. A model was developed

237 following Fishbein and Ajzen’s reasoned action model (Ajzen, 2011). The model showed strong

238 significance of work unit commitment to food safety as a key driver of the food safety behaviours of food 239 handlers. The system research meets 11 of the 12 NRC guidelines (Figure 2) as it is not clear from 240 publically available material how alternative explanations of the findings were explored. 


\subsubsection{De Boeck model}

This system was developed by Elien De Boeck in 2015 as part of her doctorate work at the

243 University of Gent (De Boeck, Jacxsens, Bollaerts, Uyttendaele, \& Vlerick, 2016; De Boeck et al., 2015).

244 The researchers use the terms culture and climate interchangeably in their research. Food safety culture,

245 they defined as the interplay of the food safety climate as perceived by the employees and the managers of

246 a company (so called 'human route') and the context in which a company is operating, the current

247 implemented FSMS, consisting out of control and assurance activities (so called 'techno-managerial

248 route') resulting in a certain (microbiological) output whilst food safety climate was considered as

249 employees' (shared) perception of leadership, communication, commitment, resources and risk awareness

250 concerning food safety and hygiene within their current work organization (De Boeck et al., 2015).

251 However, the authors themselves state that the concepts remain vague and with no unanimous definitions

252 (De Boeck et al., 2015); therefore, for the purpose of this analysis no differentiation is made between the

253 terms in evaluating the De Boeck model. The system is focused on the food safety domain and piloted at

254 eight affiliates of a large, centrally coordinated meat distribution company in Belgium. The model

255 consists of five indicators, with 27 sub-indicators, assessed through a self-assessment survey. A detailed

256 study was completed in eight butcheries and butcher shops in Belgium, and though a small sample, some

257 statistical differences were detected in the food safety climate of the participating organizations. The

258 authors define culture and climate and it is not apparent how precisely these definitions are based on

259 existing research (C. J. Griffith et al., 2010a; Frank W. Guldenmund, 2007; Schein, 2004) in the domains

260 of culture and climate. The research meets nine of the 12 NRC guidelines (Figure 2) as it is not clear from

261 publically available material how comprehensive the literature review was that lead to the model, how

262 alternative explanations of the findings are explored, and if there is a potential impact of systematic bias. 


\subsubsection{Denison model}

This system was developed by Dan Denison in 1989 and applied extensively with global the people safety domain and is therefore broader than food safety culture. It consists of four traits assessed through a self-assessment survey. Details of the research have been widely published in books and peer reviewed papers. This method represents the strongest proof of validity based on both quantitative and qualitative research and documented evidence against all 12 NRC guidelines are

271 available in publically available material (Figure 2).

\subsubsection{Jespersen model}

This system was developed by Lone Jespersen in 2010 as part of her Masters work and 274 subsequently her Doctoral work in 2014 at the University of Guelph (Jespersen et al., 2016; Jespersen \& 275 Huffman, 2014). Jespersen et al (2016) state that food safety culture in food manufacturing is rooted in 276 the definition, dimensions, and characteristics of organizational culture, as defined by Schein (2004). The 277 system is focused on the food safety domain and consists of five capability areas. The system was tested 278 with a global food manufacturing company in North America. The evaluation was conducted using triangulation between self-assessment survey; behavioral observations and interviews; and performance assessments and made use of combined deductive and inductive content analysis and quantitative self-

281 assessment data. The research makes use of both quantitative and qualitative research methods and the 282 results were evaluated using a food safety maturity model. The authors openly declare a validation gap 283 since the system was tested in one organization and to demonstrate the validation principle of 284 generalizability the model needs to be tested on other organizations. The system research meets eight of 285 the 12 NRC guidelines (Figure 2) as it is not clear from publically available material how comprehensive 
the literature review was that lead to the development of the model, how alternative explanations of the

287 findings are explored, and if there is a potential impact of systematic bias.

\subsubsection{TSI model}

289 This system was developed by TSI in 2015 and applied to food service in Dubai and small food 290 manufacturers in the U.K ( J. Taylor, Garat, J. P., Simreen, S., \& Sarieddine, G., 2015). The authors 291 describe food safety culture as prevailing attitudes, values and practices related to food safety that are 292 taught, directly and indirectly, to new employees. The system was built on research in the area of HACCP 293 application conducted in U.K. small and medium size companies and food service restaurants (Gilling, 294 2001; E. A. Taylor \& Taylor, 2004) and the authors also state that their model is based on research from a 295 broad range of academic disciplines and industry sectors (Taylor et al, 2015). The system is an audit tool 296 and focuses on the food safety domain and consists of four categories assessed through a self-assessment 297 survey. Collectively the four categories cover 16 factors and when applied commercially the findings 298 from the self-assessment survey were reported and discussed with clients. It is not clear from the 299 publically available material how the detailed 16 factors were derived and details regarding research 300 methods and validation strategies for this model were not published.

\subsubsection{Wright model}

This system was developed by Wright, Leach and Palmer on commission for the U.K. Food

303 Standards Agency (FSA) and intended for use by the agency’s public health inspectors (Wright \& Leach, 304 2013). The authors use the Griffith et al (2010) definition of food safety culture and the system is focused 305 on the food safety domain and consists of eight elements. The elements are assessed using a self306 assessment scale and behavioral observations. The system research meets nine of the 12 NRC guidelines 307 as it is not clear from publically available material how alternate explanations were explored, how 308 potential systemic bias was assessed, and the material was not submitted for peer-review. 


\subsubsection{CEB model}

The system was developed by CEB (CEB, 2016) and makes use of a five level maturity model

311 evaluating quality culture across five categories; organizational scope, employee ownership, peer

312 involvement, message credibility, and leadership emphasis (Srinivasan \& Kurey, 2014) The assessment is

313 made thorough employee self-assessment and makes use of a social cognitive model with four

314 characteristics; hear, see, transfer, and feel, in guiding actions based on the assessment. Details regarding

315 validation strategies for this model were not published.

\subsubsection{NSF model}

The system was developed by NSF (NSF, 2016) in collaboration with Cognisco Ltd. Cranfield,

318 Bedford, U.K.The basis for the system is an NSF assessment of approximately 10,000 food handlers and 319 the theories of social cognitive theory and behavioral science (Fone, 2010) The Culture Maturity system 320 has five phases that go beyond the evaluation of culture into the areas of tactics for changing behaviours 321 and evaluating a company and the efficacy of their food safety and quality management systems. The 322 system evaluates behaviour across six core markers, (1) Regulatory Governance, (2) Management 323 Systems, (3) Policies \& Standards, (4) Assessments, (5) Talent Development, and (6) Culture \& 324 Behaviours. The evaluation scores are a combination of employee self-assessment and on-site activities 325 and scores are mapped on a scale of four progressive generations, ranging from reactive to core-values.

326 Details regarding validation strategies for this model were not published (D.Fone, Personal

327 communication, November 11, 2016).

\subsection{Differences in Validation strategies}

Each of the scientifically-based culture evaluation models make use of unique validation strategies and, in exploring the differences, it was found that many models make use of internal face and 
construct validation but only two show predictive validation (Ball and Denison). Reliability testing is

332 shared in two culture evaluation systems and not clear in the remaining (Ball and Denison) (Table 2).

Table 2: Differences between the validation strategies applied in the eight culture evaluation models.

\section{Culture evaluation model Validity methodology}

Ball Internal face and construct validation through expert solicitation.
External population validation through focus groups and peer
review. Respondent validation through responds transcript
validation. Internal consistency through Cronbach’s Alpha.
Predictive validation through behavioural model and
triangulation.

De Boeck

External population validation through peer review. Internal, face and construct validation through twenty experts, cross-sector, from Belgium.

Denison

External population and historical validation through analysis of existing performance data. Internal validation through peer review and expert solicitation. Internal construct and predictive validation through correlation analysis using the Survey of Organizations and The Organizational Survey Profile data. Reliability through stability of time.

Jespersen External population and ecological validation through review of existing food safety performance data and adoption language 


\section{Culture evaluation model $\quad$ Validity methodology}

from existing food safety standards. Internal construct and face
validity through an 18 member expert panel cross-sectional, fror
US, UK, and Canada, consisting of academicians and
practitioners. Predictive validation through behavioural mode
and triangulation.
External population and ecological validation through focus
groups. Internal construct and face validation through expert
solicitation and transparency in audit trail through publically
available reports.

\subsection{System Content comparison}

The finidings from the content analysis provided data for comparison of the content between the

338 eight culture evaluation systems. It should be noted that not all systems apply the food safety culture

339 definition introduced earlier. The content was grouped to provide a graphical representation of dimension

340 coverage by each culure evaluation system (Figure 3). 


\begin{tabular}{|c|c|c|c|c|c|c|c|}
\hline $\begin{array}{c}\text { Constructs } \\
\text { (Ball) }\end{array}$ & $\begin{array}{l}\text { Indicators } \\
\text { (De Boeck) }\end{array}$ & $\begin{array}{c}\text { Traits } \\
\text { (Derison) }\end{array}$ & $\begin{array}{l}\text { Drivers } \\
\text { (CEB) }\end{array}$ & $\begin{array}{l}\text { Capability area } \\
\text { (Jespersen) }\end{array}$ & $\begin{array}{c}\text { Markers } \\
\text { (NSF) }\end{array}$ & $\begin{array}{c}\text { Categories } \\
\text { (TSI) }\end{array}$ & $\begin{array}{l}\text { Elements } \\
\text { (Wright) }\end{array}$ \\
\hline $\begin{array}{l}\text { Management } \\
\text { commitment }\end{array}$ & Leadership & Mission & $\begin{array}{l}\text { Leadership } \\
\text { emphasis }\end{array}$ & Perceived Value & $\begin{array}{l}\text { Culture and } \\
\text { Awareness }\end{array}$ & Purpose & $\begin{array}{c}\text { Perception of } \\
\text { safety }\end{array}$ \\
\hline $\begin{array}{l}\text { Supervisor } \\
\text { commitment }\end{array}$ & Commitment & Involvement & $\begin{array}{l}\text { Message } \\
\text { credibility }\end{array}$ & People systems & Management & People & Business priority \\
\hline Training & Communication & Consistency & involvement & Process thinking & Training & Process & Leadership \\
\hline $\begin{array}{c}\text { Infrastructure } \\
\text { support }\end{array}$ & Resources & Adaptability & $\begin{array}{l}\text { Employee } \\
\text { ownership }\end{array}$ & $\begin{array}{l}\text { Technology } \\
\text { enabler }\end{array}$ & $\begin{array}{l}\text { Regulatory } \\
\text { Compliance }\end{array}$ & Proactivity & $\begin{array}{l}\text { Ownership of } \\
\text { safety }\end{array}$ \\
\hline $\begin{array}{c}\text { Worker } \\
\text { commitment }\end{array}$ & Risk awareness & & 8 & $\begin{array}{c}\text { Tools and } \\
\text { infrastructure }\end{array}$ & $\begin{array}{l}\text { Policies and } \\
\text { standard }\end{array}$ & & Competence \\
\hline \multirow[t]{3}{*}{$\begin{array}{c}\text { Worker } \\
\text { behaviours }\end{array}$} & & & & & Auditing & & $\begin{array}{c}\text { Employee } \\
\text { communication }\end{array}$ \\
\hline & & & & & Traceability & & $\begin{array}{c}\text { Employee } \\
\text { involvement }\end{array}$ \\
\hline & & & & & IT Systems & & Risk perception \\
\hline
\end{tabular}

Figure 2: Content comparison of the eight culture evaluation systems. Five affinity groupings emerged from the analysis; red = values and mission, green $=$ people systems, blue $=$ consistency, yellow $=$ adaptability, and purple $=$ risk and hazards

As such, five dimensions of food safety culture were identified, which all culture evaluation

346 systems cover to varying degrees. The dimension are Values and mission, People systems, Consistency,

347 Adaptability, and Risk awareness. 


\subsubsection{Values and mission}

This dimension covers cultural content related to 1) management and employee commitment to 351 food safety (Ball, De Boeck, Taylor), 2) how leadership sets objectives, motivates, and addresses food

352 safety (De Boeck), 3) direction for the organization (Denison), 4) the organization’s perceived value and

353 priorities related to food safety (Jespersen, Wright), and 5) food safety ownership (Wright). Wright covers

354 this dimension in four of the eight elements and Ball also covers this in three of six constructs. As such, 355 Ball and Wright have the most detail of any of the cultural evaluation systems in this dimension.

\subsubsection{People systems}

This dimension covers cultural content related to 1) knowledge, qualifications, and team 358 effectiveness (Ball), 2) training, integration of new employees, and expectations of competency level 359 (Ball, De Boeck, Jespersen, Taylor), 3) leaders and employees’ communication of food safety (De Boeck, 360 Wright), 4) actual and expected involvement, autonomy, degree of membership input (Denison, Taylor, 361 Wright), 5) expectations of tasks or behaviours (Jespersen), 6) knowledge of risk (Wright). Wright covers 362 this dimension in three of the eight elements of the model and provides the most detail around this 363 dimension. Wright is also the only one that includes "risk" in the people system dimension. Ball covers 364 this dimension in two of six constructs and is the only one that speaks of "infrastructure" as part of the 365 people system and how this drives food handler food safety behaviours.

\subsubsection{Consistency}

This dimension covers cultural content related to; 1) degree of following rules (Ball, Taylor), 2)

368 good procedures and instructions are in place (De Boeck), 3) systems are enforced vs. allowance for by-

369 passing (Denison), 4) technology enabled behaviours (Jespersen), 5) access to the right tools and

370 investment in infrastructure (Jespersen). Jespersen covers this in two of five capability areas and Wright 371 does not cover this dimension directly in any elements. 
Dimension covers cultural content related to; 1 ) how the organization embraces or resists change

374 (Denison, Taylor), 2) how problem solving is approached (Jespersen). Three cultural evaluation systems 375 cover this dimension but no direct relation was found in Ball, De Boeck, and Wright.

\subsubsection{Risk awareness}

Dimension covers cultural content related to; 1) risks are known, under control, and employees

378 are alert to actual and potential food safety risks (De Boeck, Wright). De Boeck and Wright are the only

379 ones that identify this as a separate indicator. Others have risk awareness incorporated in other

380 dimensions but have not assigned as much importance to this dimension as De Boeck and Wright.

\section{$381 \quad 3.4$ Suggested framework to unify the research field}

Based on the analysis of the eight evaluation models and the above discussion a five dimension

383 framework is suggestd to provide some unification of the food safety culture research field. These

384 dimension were found to most extensively cover the content of the existing models and that found in

385 supporting literature (Figure 3). 


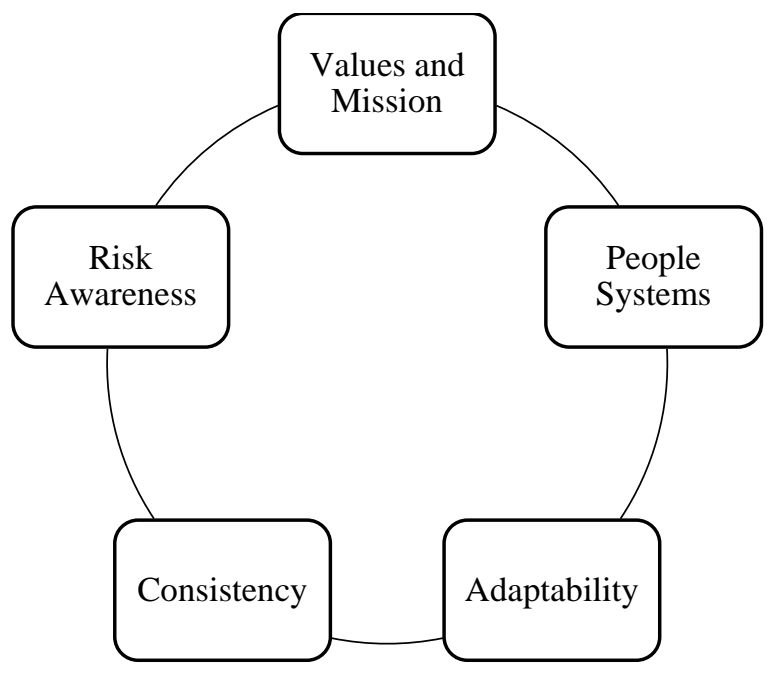

Figure 3: Food Safety Culture - Dimensional Framework

\subsection{Discussion and conclusion}

Five scientifically-based and three commercial culture evaluation models were within the scope

390 of the comparative analysis; Ball, CEB, Denison, De Boeck, Jespersen, NSF, TSI, and Wright. Analysis

391 included whether the models had been applied in the food industry and therefore directly relevant for the

392 evaluation of food safety culture. Each system was evaluated for compliance to the National Research

393 Council (NRC) guidelines (Richard J. Shavelson and Lisa Towne, 2002), through a comparison of

394 validation strategies, and through results from analysis of available textual data using content analysis.

395 Differences were found in the degree to which the systems were developed according to NRC guidelines,

396 from meeting all to meeting five of the research quality ptinciples (reference). The largest gap was the

397 lack of evidence in the assessment of systemic bias and its documentation. Ball and Denison were found

398 to do this well through transparent assessment of literature and documented path between literature

399 findings and research outcomes. The second area where weaknesses were discovered was related to the

400 assessment of data for alternative interpretation of results. Again, Ball and Denison were found to cover 
this most comprehensively through discussion of focus group discoveries and missing evidence around 402 impact on culture assessment through organizational levels.

Validation and reliability measures are important for the validity of any type of research (Louis

404 Cohen, 2007; Robson \& Robson, 2011). Validation and reliability measures were reviewed and sorted 405 according to type of research conducted. Each culture evaluation system was analyzed for the validation 406 strategy applied. Most make use of external validation through population, ecology, and peer review. 407 Only the Ball and Denison models document predictive validity. Ball constructed a predictive model 408 based on the Reason Action model and Denison showed a predictive relation between strength of culture 409 assessment and existing financial and organizational performance data. Few models document reliability 410 measures and this is considered a considerable gap. Again, Ball and Denison do incorporate reliability 411 measures into their models and document the method chosen to do this in detail. Content was compared through content analysis of the textual data. It was found that almost all 413 culture evaluation systems contain some content related to an organization's values and mission. The 414 Wright model dedicates four of five elements to this dimension. Five of the six culture evaluation systems 415 cover content related to people systems. Four of the six cultural evaluation systems cover consistency and 416 Jespersen was found to cover this in three of five dimensions. Adaptability was covered by the models of 417 Ball, Denison, whereas the Taylor and Ball models dedicated two of six constructs to this dimension. Risk 418 awareness was only covered in detail by the De Boeck and Wright models. The content findings suggest 419 that the proposed five dimensions cover all of what each system independently cover and it suggests some 420 areas that could be strengthened in some systems e.g., adaptability, consistency and risk awareness. By 421 reviewing the detailed basic, organizing, and global themes, it is clear that by looking at all content from 422 all systems a very strong picture of not simply organizational culture but food safety culture emerges. It is 423 concluded that the five proposed dimensions could be used to unify research in the food safety culture 
424 domain and also provide each system owner with input into the continuous improvement of each system 425 independently.

The analysis of NRC compliance rate and validation strategy provides information about the

427 quality and trustworthiness of the culture evaluation systems; both of which are critical characteristics of

428 research leading to culture evaluation systems by which food manufacturers make decisions regarding 429 resources for culture transformation. It was surprising to find few of the culture evaluation systems had 430 documented reliability measures and predictable validation strategies. Also, few made use of structured 431 triangulation, a method commonly applied to qualitative and mixed method research (Denzin, 2012) and a 432 method to validate research findings. It was also unexpected that systems named climate and those named 433 culture had such great similarities in content. If these terms were used consistently and according to 434 historical textual data then it might help guide the specialization of content and truly deliver on both 435 climate and culture evaluation systems. It was an unexpected finding that the global themes and suggested 436 food safety culture dimensions resemble organizational culture dimensions with the important exception 437 of the dimension Risk awareness, which appears to be more specific to food safety. One limitation of the 438 research is the lack of detailed access to the methods behind the Taylor and CEB culture evaluation 439 systems. More documented details for each of these two systems could have contributed further to the 440 comparative analysis.

442 learned and shared among people (C. J. Griffith et al., 2010a; Schein, 2004). It is based on accepted 443 assumptions, values, and beliefs, is dynamic and impacted by an array of factors and situations. By 444 evaluating culture, food manufacturers can get a snap-shot of strengths and weaknesses and make 445 decisions about actions and resources. Such decisions can make the difference between a group’s 446 assumptions and beliefs regarding food safety practices; whether or not to implement them; and 
subsequently if consumers are put in harms way or not. Hence the research behind a culture evaluation system must optimize quality, trustworthiness, and cover the broadest possible content to inform the food manufacturer correctly. These results must be given the same importance of quality and trustworthiness as, for example, microbiological testing, sampling for presence of allergens, and detecting metal contamination. The lack of an appropriate food safety culture is an emerging risk (C. J. Griffith, K. M.

Livesey, \& D. A. Clayton, 2010b) and both academicians and practitioners must hold each other to a high standard to minimize this risk. It is suggested that more research is conducted in the field of unifying food safety dimensions through a common glossary, empirical research and predictive studies and to develop models to assess the maturity of food safety culture within organizations based on these dimensions.

\subsection{Acknowledgements}

The authors would like to acknowledge the owners of the systems in scope of this analysis; Brita Ball,

Elien De Boeck, Dan Denison, Dan Fone, Ryan Hadley, Joanne Taylor, and Michael Wright,

\subsection{References}

Ajzen, I. (2011). The theory of planned behaviour: Reactions and reflections. Psychology \& Health, 26(9), 1113-1127. doi:10.1080/08870446.2011.613995

Armijo-Olivo, S., Stiles, C. R., Hagen, N. A., Biondo, P. D. and Cummings, G. G. (2012). Assessment of study quality for systematic reviews: a comparison of the Cochrane Collaboration Risk of Bias Tool and the Effective Public Health Practice Project Quality Assessment Tool: methodological research. Journal of Evaluation in Clinical Practice, 18: 12-18. .

Attride-Stirling, J. (2001). Thematic networks: An analytic tool for qualitative research. Qualitative Research, 1(3), 385-405.

Ball, B., Wilcock, A., \& Aung, M. (2009). Factors influencing workers to follow food safety management systems in meat plants in Ontario, Canada. International journal of environmental health research, 19(3), 201-218. doi:10.1080/09603120802527646

Bernd Appel, G.-F. B. l., Matthias Greiner, Monika Lahrssen- Wiederholt und Andreas Hensel. (2011). EHEC-Ausbruch 2011. Retrieved from

Borsboom, D. M., Gideon J.; van Heerden, Jaap. (2004). The Concept of Validity. Psychological Review, Vol 111(4), Oct 2004, 1061-1071.

Cameron, K., \& Quinn, R. (2006). Diagnosing and changing organizational culture : Based on the competing values framework . : San Francisco: Jossey-Bass.

Canadian Food Inspection, A. (2013). [Action on Weatherill Report Recommendations to Strengthen the Food Safety System: Final Report to Canadians]. Web Page. 
CEB. (2016). www.cebglobal.com/innovation-strategy/quality/culture-of-quality.html.

De Boeck, E., Jacxsens, L., Bollaerts, M., Uyttendaele, M., \& Vlerick, P. (2016). Interplay between food safety climate, food safety management system and microbiological hygiene in farm butcheries and affiliated butcher shops. Food Control, 65, 78-91. doi:http://dx.doi.org/10.1016/j.foodcont.2016.01.014

De Boeck, E., Jacxsens, L., Bollaerts, M., \& Vlerick, P. (2015). Food safety climate in food processing organizations: Development and validation of a self-assessment tool. Trends in Food Science \& Technology, 46(2, Part A), 242-251. doi:http://dx.doi.org/10.1016/j.tifs.2015.09.006

Denison, D. R. (1997). Corporate Culture and Organizational Effectiveness: Denison Consulting; 2nd edition (May 1997).

Denison, D. R., \& Mishra, A. K. (1995). Toward a Theory of Organizational Culture and Effectiveness. Organization Science, 6(2), 204-223.

Denison, D. R. H. N. L., and Colleen Lief. (2012). Leading Culture Change in Global Organizations: Aligning Culture and Strategy. John Wiley \& Sons.

Denzin, N. K. (2012). Triangulation 2.0. Journal of Mixed Methods Research, 6(2), 80-88. doi:10.1177/1558689812437186

Feuer, M. J., Towne, L., \& Shavelson, R. J. . (2002). Scientific culture and educational research. . Educational Researcher, 31(8), 4-14.

Gersten, R., Baker, S., \& Lloyd, J. (2000). Designing high-quality research in special education. The Journal of Special Education, 34(1), 2-18.

Gilling, S. J. (2001). Successful Hazard Analysis Critical Control Point Implementation in the United Kingdom: Understanding the Barriers through the Use of a Behavioral Adherence Model. Journal of Food Protection, 64, 710-715.

Gossner, C. M. E., Schlundt, J., Ben Embarek, P., Hird, S., Lo-Fo-Wong, D., Beltran, J. J. O., . . . Tritscher, A. (2009). The Melamine Incident: Implications for International Food and Feed Safety. Environ Health Perspect, 117(12), 1803-1808. doi:10.1289/ehp.0900949

Graneheim, U. L., B. (2004). Qualitative content analysis in nursing research: Concepts, procedures and measures to achieve trustworthiness. Nurse Education Today, 24, 105-112.

Greenhalgh, T. (1997). Assessing the methodological quality of published papers. . BMJ : British Medical Journal, 315(7103), 305-308.

Griffith, C. J. (2010). Do businesses get the food poisoning they deserve? British Food Journal, 112(4), 416-425. doi:10.1108/00070701011034420

Griffith, C. J., Livesey, K. M., \& Clayton, D. (2010a). The assessment of food safety culture. British Food Journal, 112(4), 439-456. doi:10.1108/00070701011034448

Griffith, C. J., Livesey, K. M., \& Clayton, D. A. (2010b). Food safety culture: the evolution of an emerging risk factor? British Food Journal, 112(4), 426-438. doi:10.1108/00070701011034439

Gronlund, N. L., Robert L. (1990). Measurement and Evaluation in Teaching.

Guldenmund, F. W. (2000). The nature of safety culture: a review of theory and research. Safety Science, 34(1-3), 215-257. doi:http://dx.doi.org/10.1016/S0925-7535(00)00014-X

Guldenmund, F. W. (2007). The use of questionnaires in safety culture research - an evaluation. Safety Science, 45(6), 723-743. doi:http://dx.doi.org/10.1016/j.ssci.2007.04.006

Howe, K., \& Eisenhart, M. (1990). Standards for Qualitative (and Quantitative) Research: A Prolegomenon. Educational Researcher, 19(4), 2-9. doi:10.3102/0013189x019004002

Incident, G. I. i. t. W. P. C. C. (2014). The WPC80 incident: Causes and responses government InquIry Into the Whey ProteIn Concentrate ContamInatIon IncIdent.

Ingelfinger , J. R. (2008). Melamine and the Global Implications of Food Contamination. New England Journal of Medicine, 359(26), 2745-2748. doi:doi:10.1056/NEJMp0808410 
562

563

564

565

566

567

568

569

570

571

572

573

Jespersen, L., Griffiths, M., Maclaurin, T., Chapman, B., \& Wallace, C. A. (2016). Measurement of food safety culture using survey and maturity profiling tools. Food Control, 66, 174-182. doi:http://dx.doi.org/10.1016/j.foodcont.2016.01.030

Jespersen, L., \& Huffman, R. (2014). Building food safety into the company culture: a look at Maple Leaf Foods. Perspectives in Public Health(May 8, 2014). doi:10.1177/1757913914532620

Louis Cohen, L. M. a. K. M. (2007). Research Methods in Education (Vol. Sixth edition).

Meyrick, J. (2006). What is good qualitative research? . Journal of Health Psychology, 11(5), 799-808.

NSF. (2016). www.nsffoodeurope.com/service.asp?service_id=consulting\&subservice_id=9\&servicepage_id=127.

Nyarugwe, S. P., Linnemann, A., Hofstede, G. J., Fogliano, V., \& Luning, P. A. (2016). Determinants for conducting food safety culture research. Trends in Food Science \& Technology, 56, 77-87. doi:http://dx.doi.org/10.1016/j.tifs.2016.07.015

Pennington, H. (2009). The Public Inquiry into the September 2005 Outbreak of E.coli O157 in South Wales. Retrieved from

Pennington, T. H. (2014). E. coli O157 outbreaks in the United Kingdom: past, present, and future. Infection and Drug Resistance, 7, 211+.

Powell, D. A., Jacob, C. J., \& Chapman, B. J. (2011). Enhancing food safety culture to reduce rates of foodborne illness. Food Control, 22(6), 817-822. doi:10.1016/j.foodcont.2010.12.009

Richard J. Shavelson and Lisa Towne. (2002). Scientific Research in Education Research: National Research Council and The National Academies Press.

Richie, J. L., J. (2003). Qualitative Research Practice - A Guide for Social Science Students and Researchers: SAGE Publications.

Roberts, P., \& Priest, H. . (2006). Reliability and validity in research. . Nursing Standard, 20(44), 41+. Retrieved from http://go.galegroup.com.subzero.lib.uoguelph.ca/ps/i.do?p=AONE\&sw=w\&u=guel77241\&v=2.1 \&it=r\&id=GALE\%7CA149022548\&asid=467ae8ef2228c61c7546df411b0db083.

Robson, C., \& Robson, C. (2011). Real world research : a resource for users of social research methods in applied settings. Chichester, West Sussex: Chichester, West Sussex : Wiley.

Schein, E. H. (2004). Organizational culture and leadership. San Francisco: San Francisco : Jossey-Bass. Seward, S. (2012). Assessing the food safety culture of a manufacturing facility. Food technology, 66(1), 44.

Shepard, L. A. (1993). Evaluating Test Validity. Review of Research in Education, 19(Jauary 1993), 405450.

Shepard, L. A. (2016). Evaluating test validity: reprise and progress. Assessment in Education: Principles, Policy \& Practice, 23(2), 268-280. doi:10.1080/0969594X.2016.1141168

Srinivasan, A., \& Kurey, B. (2014). Creating a Culture of Quality. Harvard Business Review, 92(4), 2325.

T. Long, M. J. (2000). Rigour, reliability and validity in qualitative research. Clinical Effectiveness in Nursing, 4(1), 30-37.

Taylor, E. A., \& Taylor, J. Z. (2004). Using qualitative psychology to investigate HACCP implementation barriers. International journal of environmental health research, 14(1), 53-63. doi:10.1080/09603120310001633877

Taylor, J., Garat, J. P., Simreen, S., \& Sarieddine, G. (2015). An industry perspective: A new model of Food Safety Culture Excellence and the impact of audit on food safety standards. Worldwide Hospitality and Tourism Themes, 7(1), 78-89. Retrieved from http://sfx.scholarsportal.info/guelph/docview/1648846697?accountid=11233.

Trochim, W. M. K. (2006). Research Methods Knowledge Base. Reliability and Validity. Retrieved from http://www.socialresearchmethods.net/kb/relandval.php 
574

575

576

577

578

579

580

581

582

583

584

585

586

587

588
Weiser, A. A., Thöns, C., Filter, M., Falenski, A., Appel, B., \& Käsbohrer, A. (2016). FoodChain-Lab: A Trace-Back and Trace-Forward Tool Developed and Applied during Food-Borne Disease Outbreak Investigations in Germany and Europe. PLoS ONE, 11(3), 1-11. doi:10.1371/journal.pone.0151977

Wilcock, A., Ball, B., \& Fajumo, A. (2011). Effective implementation of food safety initiatives: Managers', food safety coordinators' and production workers’ perspectives. Food Control, 22(1), 27-33. doi:10.1016/j.foodcont.2010.06.005

Wright, M., \& Leach, P. (2013). Achieving an effective food hygiene culture: the next step in assuring excellence. International Food Hygiene, 24, 21-23.

Yiannas, F. (2009). Food safety culture creating a behavior-based food safety management system: New York : Springer, c2009. 